\title{
LITERASI HAZARD DAN PROTEKSI KEBAKARAN BAGI SISWA SMK MUHAMMADIYAH 01 PADANG
}

\author{
Ana Susanti Yusman ${ }^{1)}$, Febrimen Herista ${ }^{2)}$, Asiya Nurhasanah Habirun ${ }^{3)}$ \\ ${ }^{1,2,3}$ Fakultas Teknik, Universitas Muhammadiyah Sumatera Barat, Padang \\ email: anasusantiyusman@umsb.ac.id
}

Submit : 05/10/2021| Accept : 01/11/2021| Publish: 30/12/2021|

\begin{abstract}
Muhammadiyah 01 Vocational High School Padang is the school with engineering concentration such as automotive, electrical, computer and network technology. The potential of hazards for school are: fire; exposure to radiation, electrical, and physical and the high potential places are : workshops, laboratories and classrooms. In addition, knowledge of HAZARD / Fire was given for 14 students of year X of SMK Muhammadiyah 01 Padang from various majors. The methods were used lecture and discussion. We did pretest and posttest in order to have participants knowledge. To sum up students' understanding of Hazard in general was $42 \%$ during the pre-test and increased to $50 \%$ during the posttest. However, the data were analyzed statistically and showed that there was an increase, constant and decrease of student understanding as follows: an increase from 25\% to $75 \%$ for TBSM students (Motorcycle Business Engineering); constant 100\% for RPL (Software Engineering) students; constant $30 \%$ for TITL students (Electrical Installation Engineering); constant 30\% for TKJ (Computer and Network Engineering) students and a decrease from 60\% to 30\% for TPM (Mechanical Engineering) students. In conclusion, students of RPL, TKJ and TPM need to be given intense training on HAZARD and fire protection to improve their skills.
\end{abstract}

Keywords: Literacy, Hazard, Fire Protection, Vocational High School, Studen

\begin{abstract}
Abstrak
SMK M01 adalah sebuah institusi pendidikan kejuruan dengan konsentrasi teknologi otomotif, listrik, komputer dan jaringan. Potensi Hazard/bahaya di sekolah adalah kebakaran, terpapar radiasi (kimia, biologi, infeksi, alergi, listrik, dan fisik). Tempat yang berpotensi tinggi untuk Hazard/bahaya adalah bengkel, laboratorium dan kelas. Pengetahuan tentang HAZARD dan Proteksi Kebakaran ini diberikan kepada 14 orang siswa kelas X SMK Muhammadiyah 01 Padang dari berbagai jurusan. Metode yang digunakan adalah ceramah dan diskusi sedangkan evaluasinya menggunakan pre test dan post test untuk diobservasi lebih lanjut. Pengetahuan siswa tentang Hazard dan Proteksi Kebakaran secara umum sebesar $42 \%$ saat pre-test dan meningkat menjadi 50\% saat post-test. Guna mengetahui lebih rinci maka data dianalisa dengan menggunakan regresi linier sederhana dan disimpulkan terjadi kenaikan dari $25 \%$ menjadi 75\% untuk siswa TBSM (Teknik Bisnis Sepeda Motor); konstant 100\% untuk siswa RPL(Rekayasa Perangkat Lunak); konstant 30\% untuk siswa TITL (Teknik Instalasi tenaga listrik); konstant $30 \%$ untuk siswa TKJ (Teknik komputer dan jaringan) serta penurunan dari $60 \%$ menjadi $30 \%$ bagi siswa TPM (Teknik Permesinan). Dengan demikian siswa yang berasal dari jurusan RPL, jurusan TKJ dan jurusan TPM perlu diberikan literasi yang intens tentang HAZARD dan Proteksi Kebakaran untuk meningkatkan ketrampilan mereka.
\end{abstract}

Kata Kunci: Literasi, Bahaya, Proteksi Kebakaran, SMK, Pelajar

\section{PENDAHULUAN}

Secara umum Hazard adalah bahaya merupakan sumber potensi kerusakan atau situasi yang berpotensi untuk menimbulkan kerugian. Sesuatu disebut sebagai sumber bahaya hanya jika memiliki risiko menimbulkan hasil yang negatif. Keselamatan kerja adalah upaya-upaya yang ditujukan untuk melindungi pekerja; menjaga keselamatan orang lain; 
melindungi peralatan; tempat kerja dan bahan produksi; menjaga kelestarian lingkungan hidup dan melancarkan proses produksi. Ini berlaku di semua tempat sesuai dengan pasal 2 UU 1 / 1970/Tentang Keselamatan Kerja. Siswa SMK M01 yang akan melakukan praktek di bengkel/ workshop harus diberikan bekal pengetahuan tentang K3 (Kesehatan dan Keselamatan Kerja) terutama mengenai potensi bahaya kebakaran dan cara menanggulanginya.

Tujuan dari kegiatan pengabdian masyarakat pada siswa SMK M01 Padang adalah untuk memberikan pengetahuan dan ketrampilan tentang potensi bahaya (Hazard)secara umum, bahaya kebakaran dan proteksinya Beberapa penelitian dan pengabdian masyarakat terdahulu tentang K3 ini adalah sebagai berikut: (Lestariani1) Nanis Hairunisya2) Imam Suwaktus Suja'3), (2020) menjelaskan bahwa Peranan materi K3 ( Kesehatan dan Keselamatan Kerja ) terhadap sikap ,sikap dan perilaku mampu membuat siswa mengubah kebiasaan-kebiasaan yang buruk pada saat praktek di lab Tata Boga.

Tidak membahayakan bagi dirinya dan orang lain yang ada didalam lab tersebut, dan mencegah terjadinya resiko kecelakaan yang bisa merugikan semuanya. Penelitian yang dilakukan oleh (Yusman, 2019) menjelaskan bahwa $85 \%$ mahasiswa FT UMSB yang sedang praktek di laboratorium menunjukkan sikap dan kesadaran berprilaku K3 dengan katagori sangat baik.

$$
\text { Selanjutnya }
$$

(Mohammad

Farid1,Windy Claudia Anggraini2, 2021) berpendapat bahwa ada 4 sumber bahaya yang menyebabkan kecelakaaan kerja pada karyawan yaitu sikap pekerja, peralatan kerja, benda asing dan lantai basah. Hasil penelitian (Yamin, 2020) mengatakan bahwa aspek pengetahuan, sikap dan tindakan K3 bagi siswa SMKN 2 Sidenreng dalam melaksanakan praktikum pada kualifikasi baik. Hasil dari kegiatan pengabdian masyarakat (Nur Asniati Djaali1)Syarif Usman2)Rano Agustino3)Frenta Helena Simaibang4), 2020) yang dilakukan pada siswa SMA Negeri 93 Jakarta memberikan dampak baik terhadap peningkatan pengetahuan siswa tentang potensi bahaya dan memberikan ketrampilan untuk perlindungan diri dari bahaya.

\section{METODE KEGIATAN}

Siswa diberikan pengetahuan tentang potensi bahaya yang ada di sekitar sekolah seperti yang ditampilkan tabel 1 berikut:

Tabel 1. Potensi Bahaya (Hazard)

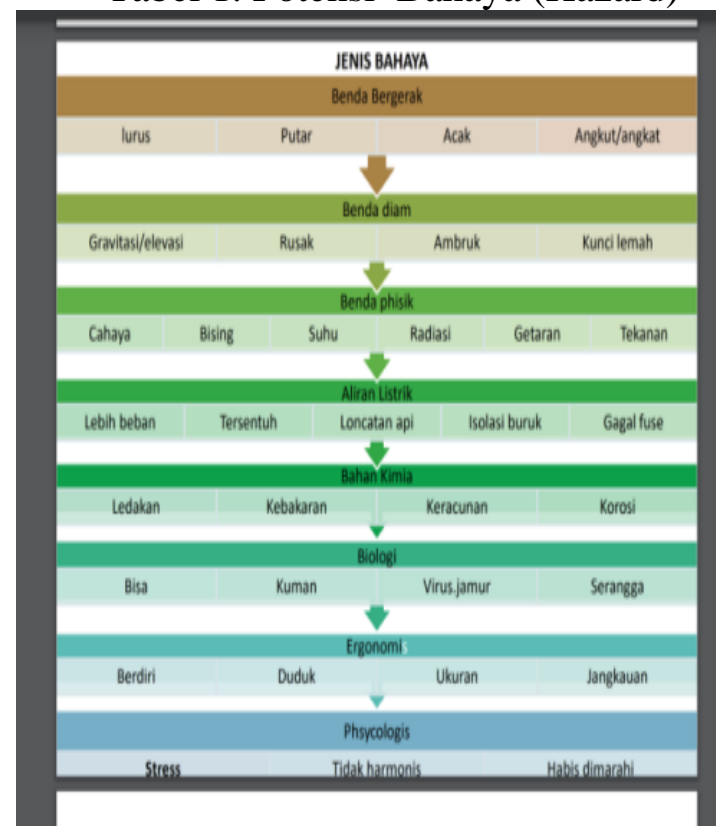

Sumber : Nasyfrizal Carlo Manajemen Resiko K3

Metode yang digunakan pada kegiatan pengabdian masyarakat ini adalah ceramah dan diskusi, sedangkan untuk mengevaluasinya digunakan form pre test dan post test. Siswa diberikan penyuluhan tentang potensi bahaya (Hazard) terutama kebakaran yang kemungkinan terjadi di sekolah. Selain itu dijelaskan juga kelasifikasi kebakaran menurut Permenaker 04/80 yang terdiri dari kebakaran kelas A pada benda padat kecuali logam, kebakaran kelas B pada 


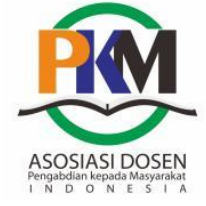

benda cair dan gas, kebakaran kelas $\mathrm{C}$ pada peralatan listrik yang masih bertegangan dan kebakaran kelas D pada logam. Alat proteksi kebakaran yang diajarkan adalah APAR (Alat Pemadam Api Ringan) dengan berbagai bahan isi yang harus dimiliki oleh setiap sekolah, perkantoran dan tempat umum. Siswa juga diberikan penyuluhan sistem kerja APAR dan cara pengoperasian APAR.

Dengan penyuluhan ini diharapkan siswa memahami penyebab bahaya berasal dari bermacam keadaan seperti benda bergerak, benda diam, benda pisik, aliran listrik, bahan kimia, biologi, ergonomis dan psikologis.

\section{HASIL DAN PEMBAHASAN}

Literasi Hazard dan Proteksi Kebakaran ini dilaksanakan pada tanggal 29 Mei 2021 bertempat di Sekolah Menengah Kejuruan Muhammadiyah 01 Padang jalan By Pass Padang. Dalam suasana pandemic Covid 19, kehadiran siswa di sekolah secara bergantian. Peserta yang mengikuti kegiatan literasi ini sejumlah 14 orang siswa yang terdiri dari jurusan Teknik Komputer dan Jaringan (TKJ) sebanyak 3 orang; jurusan Teknik Bisnis Sepeda Motor (TBSM) sebanyak 4 orang; jurusan Teknik Instalasi Tenaga Listrik ( TITL) sebanyak 3 orang; jurusan Teknik Permesinan (TPM) sebanyak 3 orang; dan jurusan Rekayasa Perangkat Lunak (RPL) sebanyak1 orang.

Dari hasil pengamatan peserta belum memahami hazard dan proteksi terhadap kebakaran dengan baik. Ini dapat dilihat dari hasil pre test secara umum dengan ratarata penilaian $42 \%$ yang berhasil menjawab secara benar 5 dari 9 soal tentang hazard dan proteksi kebakaran yang diberikan.

Dengan menggunakan regresi linier sederhana data ini diolah dan didapat persamaan garisnya $\mathrm{y}=0.0286 \mathrm{x}+3.5714$ dan $\mathrm{R} 2=0.0051$ (lihat gambar2). Ini berarti setiap pertambahan variabel peserta/siswa 1
Jurmas Sains dan Teknologi eISSN: 2775-7013

Vol. 2 No. 4

Hal:11-15

Doi: https://doi.org/10.47841/saintek.v2i4.13

orang akan meningkatkan jumlah jawaban yg benar sebesar 2,86\% sedangkan koefisein regresi sebesar 3,5714 berarti variabel siswa konstant akan meningkatkan jumlah jawaban yang benar $35,7 \%$. Untuk nilai $\mathrm{R}$ square menunjukkan bahwa $5 \%$ pertambahan siswa dapat menambah jumlah jawaban yang benar sedangkan faktor lainnya tidak termasuk didalam model.

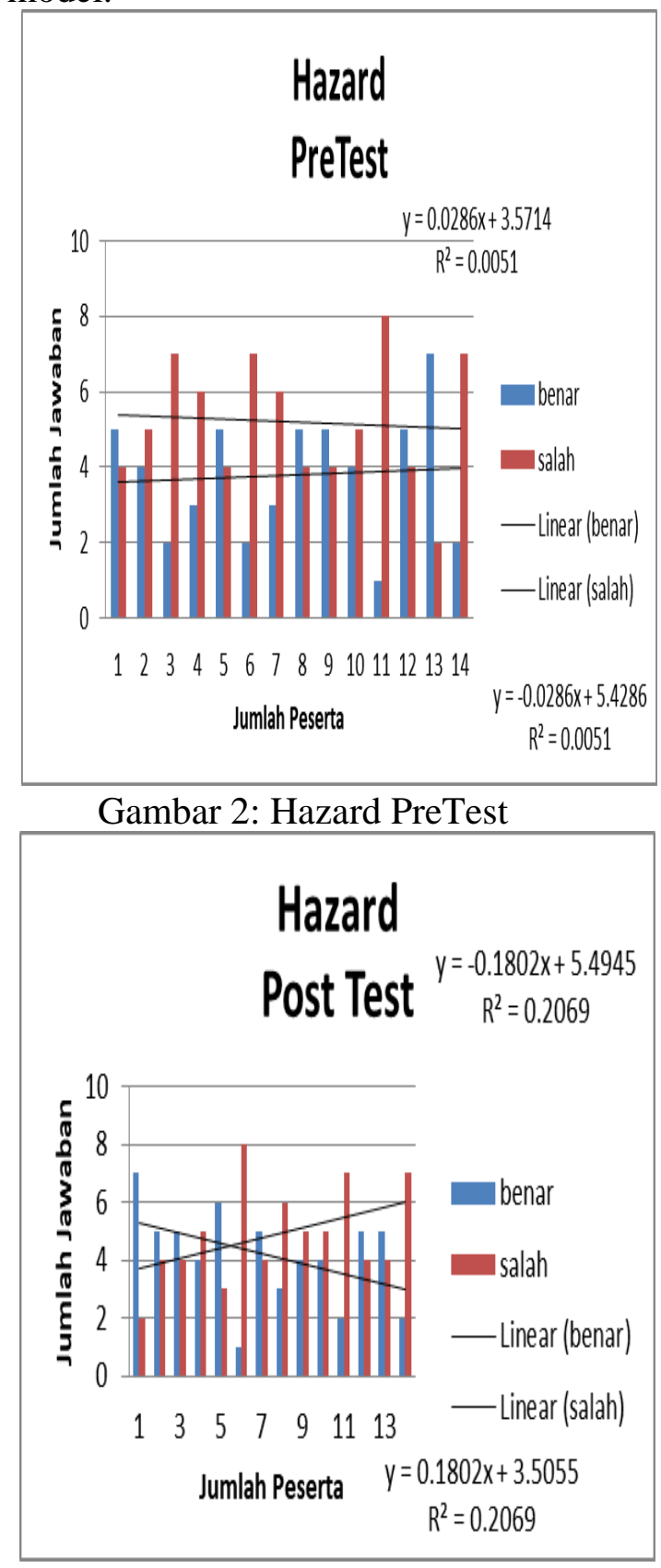

Gambar 3: Hazard Post Test 


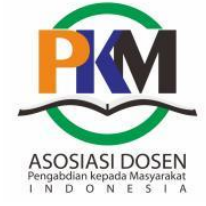

Selanjutnya siswa diberikan ceramah pengetahuan dasar tentang hazard dan proteksi kebakaran dilanjutkan dengan diskusi tanya jawab selama 90 menit. Setelah itu diadakan post test dengan menggunakan form dan hasilnya $50 \%$ dari peserta menjawab pertanyaan dengan benar (lihat gambar 3).

Dengan menggunakan regresi linier sederhana didapat persamaan garis $\mathrm{y}=$ $0.1802 x+5.4945$ dengan $\mathrm{R} 2=0,2069$ ini berarti jika terjadi pertambahan jumlah peserta/ siswa 1 orang maka akan terjadi penurunan jumlah jawaban yang benar $18 \%$ demikian sebaliknya jika jumlah peserta menurun maka jawaban yang benar akan naik 18\%. R square menunjukkan $20 \%$ bertambahnya jumlah peserta meningkatkan jumlah jawaban yang benar sedangkan faktor lainnya tidak termasuk dalam model.

Data kemudian di analisis lebih lanjut dan didapat pengetahuan dan skill siswa untuk setiap jurusan berbeda-beda yaitu: terjadi kenaikan dari $25 \%$ menjadi $75 \%$ untuk siswa TBSM ( Teknik Bisnis Sepeda Motor); stabil100\% untuk siswa RPL(Rekayasa Perangkat Lunak); konstant $30 \%$ untuk siswa TITL (Teknik Instalasi tenaga listrik); stabil 30\% untuk siswa TKJ (Teknik komputer dan jaringan) serta penurunan dari $60 \%$ menjadi $30 \%$ bagi siswa TPM (Teknik Permesinan).

\section{SIMPULAN}

Pengetahuan tentang Hazard dan ketrampilan proteksi kebakaran sangat penting dikuasai siswa SMK M01. Dari hasil analisis data disimpulkan bahwa pemahaman dan ketrampilan siswa SMK M01 tentang HAZARD dan proteksi kebakaran masih belum dikuasai terutama untuk siswa jurusan Teknik Permesinan.

Disarankan siswa untuk dapat mengikuti literasi hazard dan proteksi kebakaran lebih intens guna meningkatkan
Jurmas Sains dan Teknologi eISSN: 2775-7013

Vol. 2 No. 4

Hal:11-15

Doi: https://doi.org/10.47841/saintek.v2i4.13

skill dan mempersiapkan diri memasuki dunia kerja.

\section{UCAPAN TERIMAKASIH}

Segenap penulis mengucapkan terima kasih kepada Rektor Univ.Muhammadiyah Sumatera Barat, Ketua LPPM UM Sumatera Barat beserta tim yang sudah memberikan kesempatan dan dukungan dana untuk terlaksananya kegiatan ini.

Tak lupa juga terima kasih kepada Bapak kepala Sekolah SMK M01 Padang dan ibu Wakil Kepala Sekolah bidang kesiswaan beserta guru dan siswa SMK M01 Padang yang sudah membantu terlaksananya kegiatan ini. Semoga apa yang sudah dilakukan mendapatkan balasan pahala dari Allah SWT. Aamiin.

\section{DAFTAR PUSTAKA}

Carlo,

N.

https://slideplayer.info/slide/133723

08/. Retrieved july 10, 2021, from -: https://slideplayer.info/slide/133723 $08 /$.

Lestariani, N.H., \& Imam, S.S. (2020). penerapan materi keselamatan dan kesehatan kerja $(\mathrm{k} 3)$ terkait sikap dan kompetensi siswa tata boga smk negeri 1 pogalan trenggalek. Jurnal Inovasi Pendidikan, 1079 - 1085.

Mohammad, F., \& Windy, C. A. (2021). analisis keselamatan dan kesehatan kerja ( k3) menggunakan metode hazard dan operability ( studi kasus PT. IGASAR) . Jurnal Teknologi dan Informasi Bisnis, 223 - 227.

Djaali N. S., Syarif , U., Rano, A, Frenta, H.S. (2020). Penerapan kesehatan dan keselamatan kerja (k3) melalui sosialisasi potensi bahaya di sekolah. Jurnal Pemberdayaan Komunitas MH Thamrin, 34 - 43. 
Vol. 2 No. 4

Hal:11-15

Yamin, M. (2020). perilaku keselamatan dan kesehatan kerja (k3) siswa dalam pembelajaran praktikum di smk neger 2 sidenreng. Jurnal Syntax Admiration, 207-214.
Doi: https://doi.org/10.47841/saintek.v2i4.13

Yusman, A. S. (2019). aplikasi k3 mahasiswa teknik di labor teknik universitas muhammadiyah sumatera barat. Menara Ilmu, 6 - 10 . 